\title{
Does thoracoscopy have advantages over open surgery for asymptomatic congenital lung malformations? An analysis of 1626 resections
}

Stephen Adams a, Matthew Jobson a, Patarawan Sangnawakij b, Adam Heetun a, Anthony Thaventhiran a, Navroop Johal a, Dankmar Böhning b, Michael P. Stanton a

a Department of Paediatric Surgery, University Hospital Southampton NHS Foundation Trust, Southampton, UK

b Southampton Statistical Sciences Research Institute, University of Southampton, Southampton, UK

\section{$\underline{\text { Introduction }}$}

Although controversy exists as to the management of antenatally-diagnosed congenital lung malformations (CLM), published series describe that elective surgery is undertaken in the majority (70\%), even if they have been asymptomatic.[1-3] The apparent incidence of CLM has risen dramatically from previous reports of 1 in 30,000 , to one recent fetal register and population study estimating as high as 1 in 2,500, largely due to improvements in pre-natal sonography.[4] Therefore, increasing numbers of infants worldwide currently undergo pre-emptive surgical resection, usually lobectomy.

There are several examples of paediatric conditions where minimally-invasive surgery has demonstrable benefits in terms of analgesia requirements, smaller scars and shorter lengths of stay. However, there are also specific examples where laparoscopic surgery may have worse long-term outcomes.[5] Reports of thoracosopic lobectomy for CLM vary and some have described high conversion rates (up to 20\%) and significant complications.[6-8] 
The only previous meta-analysis of thoracoscopic and open CLM resection included 216 patients from six reports (all pre-2010), two of which described only four patients in each treatment arm.[9-11] Since this report, there has been a large number of highvolume case series of CLM resection. In addition there are a significant number of studies including only thoracosopic or open CLM resections without comparison.

In view of the increase in both the incidence and available data on surgical outcomes, we aimed to perform a systematic review and meta-analysis of the published results of thoracoscopic and open CLM resections. We chose to focus on the outcomes of surgery for asymptomatic cases - the patients in whom controversy remains as to whether conservative or surgical management should be undertaken. This focus was also to try and minimise possible selection bias of patients who were symptomatic being considered less suitable pre-operatively for a thoracoscopic approach. In order to include as many patient outcomes as possible we also aimed to further develop meta-analysis methodology. This ensured that reports including only means and sample sizes of both treatment possibilities could be compared, anticipating that most series would not include an estimate of variability.

\section{$\underline{\text { Methods }}$}

A Systematic review was undertaken following PRISMA guidelines.[12] Two independent reviewers searched Pubmed, EmBASE and Google Scholar databases using the search terms and inclusion/exclusion criteria as detailed in Table 1 for the period 2004 - 2015. The abstracts were assessed for relevance and reviewed in committee to arbitrate inclusion as necessary. Full text articles were obtained and an agreed dataset (table 1) was collected from each included paper, specifically focussing 
on operative outcomes of patients who were asymptomatic. A further two independent reviewers assessed the quality of all included articles using the Rangel scoring system, a validated quality assessment scale (published in 2003) for assessing retrospective pediatric surgical case series.[13] The mean of these scores was used to rank articles as 'poor' (0-15), 'fair' (16-30) or 'good' (31-45) quality.

Studies with comparative data of open to thoracoscopic lung lesion resection that were included in the systematic review were submitted to meta-analysis. Data were analysed using Excel ${ }^{\mathrm{TM}}$ and STATA14 ${ }^{\mathrm{TM}}$ with METAN add-on. Analysis was on an intention to treat basis for asymptomatic lung lesions and also on the same basis for thoracoscopic vs open operation. A fixed effects model (Mantel-Haenszel) was used. Forest plots were produced and heterogeneity testing $\left(\mathrm{I}^{2}\right.$ test $)$ undertaken. Funnel plots were used to assess for publication bias. Results were expressed as Odds Ratio or actual difference with $95 \%$ confidence intervals and p-value. Statistical significance was taken as $\mathrm{p}<0.05$.

Having undertaken data collection it became apparent that the majority of studies available did not include a measure of variance in the publication. When the measure of interest is a frequency, for example, when looking at the number of complications, it is possible to compute an estimate of the variance of the measure of interest such as the risk ratio from the frequency data. However, for a quantitative outcome such as the length of hospital stay or number of chest tube days, it is not possible to derive an estimate of the variance of the mean only on the basis of the mean itself and the sample size. We required this in order to be able to state if there are any significant differences between the treatment groups. 
Given a set of independent studies such as those in this study, it is possible to construct an estimate of the variance by means of cross-study information using the assumption that the study data follow a normal distribution.[14] Hence we are able to say, for the summary estimator across studies as well as for the individual studies, whether there are significant differences between treatments.

\section{Results - Systematic Review}

36 studies were included, describing 1626 CLM resections (904 thoracoscopic, 722 open). There were no randomised controlled trials. The summary data is reviewed in table 2. The quality of these studies was rated as poor on average (median Rangel score 13.8; IQR 6.5) although 14/36 (39\%) papers rated 'fair', none achieved 'good'. Follow-up data was not universally available, but averaged 403 days in the minimally-invasive group and 268 days for open resection.

Average age at resection was 17 months for thoracoscopy and 13 months for thoracotomy. 92/904 (10\%) of thoracoscopic operations were converted to open. $195 / 1626(12 \%)$ of patients were reported to have developed respiratory symptoms pre-operatively, these ranged from wheeze to recurrent infections. These patients were included in the analysis on the basis that resection of the antenatally-diagnosed lung lesion was planned irrespective of symptom development. There were no deaths and no reported cases of malignancy in antenatally-diagnosed lesions in this series.

\section{$\underline{\text { Results - Meta-analysis }}$}


12/36 papers were included in the meta-analysis representing 887 CLM resections; 404 thoracoscopic and 483 open. There was no evidence of publication bias. Heterogeneity assessment was negative $\left(I^{2}=30 \%, p=0.15\right)$. Age was not significantly different between the groups, mean 15 months, $1.4(-8-10.9)$ months older in the open group $(\mathrm{p}=0.8)$. Weight was similar in each group, mean $8 \mathrm{~kg}, 0.4(-0.2-1.0) \mathrm{kg}$ less in the open group $(\mathrm{p}=0.2)$.

Total complications occurred in 63/404 (16\%) of the analysed thoracoscopic operations and in 87/483 (18\%) of open. Total complications were significantly less frequent in the thoracoscopic group, OR $0.69(0.41-1.17, \mathrm{p}=0.018)$ (Figure 1). Individual complications were infrequent enough to preclude further analysis. Mean length of stay was 5.5 days, the forest plot showing a hospital stay $1.4(0.4-2.4)$ days shorter in the minimally invasive group $(\mathrm{p}=0.008)$ (Figure 2$)$. Operative time averaged 142 minutes and was $37(19-55)$ minutes longer for thoracoscopy $(\mathrm{p}<0.0005)$. Chest tube days were similar between the groups, averaging 3.3 days, being a non-significant $0.79(-0.02-1.59, \mathrm{p}=0.055)$ days shorter in the thoracoscopic group.

\section{$\underline{\text { Discussion }}$}

This study has demonstrated that, on the basis of available literature, thoracoscopic resection is at least as safe as open surgery for asymptomatic antenatally-diagnosed CLMs. We found the total complication rate and length of stay favoured thoracoscopy. Although we have demonstrated a significant difference in the total complication rates of open and thoracosopic resections, these were in fact quite 
similar (18\% vs $16 \%$ respectively). In our view, this could be viewed as demonstrating that thoracoscopy does not have a higher associated complication rate. Thoracoscopy was associated with a longer operative time (by 37 minutes), this was off-set by a shorter hospital stay of 1.4 days. Approximately $10 \%$ of cases started thoracoscopically were converted to open thoracotomy.

The strength of this study lies in being able to analyse a relatively large number of patient outcomes - 904 thoracoscopic vs 722 open thoracotomy, with a total of 1626 patients). The only previous meta-analysis on thoracoscopic CLM resection was published by Nasr et al in 2012. For this study, 6 studies were analysed with a total of 216 patients; in two series, very small numbers were compared -4 in each treatment arm.

A greater number of papers have become available since 2010. We have developed a meta-analysis theory[14] to allow estimates of variance from studies which only reported mean values and sample sizes. Thus we were able to compare a much larger number of series and patients.

The weakness of this study lies in the quality of available reported data. No randomised controlled trials have been published on this subject, so we relied largely on retrospective case series. According to Rangel scoring, overall study quality was on average 'poor'. Inherent bias in reporting may be present. It is possible, for example that cases considered likely to be relatively simple, i.e. small malformations, would be more likely to be offered thoracoscopy than patients with larger, complex cysts. Our focus was on asymptomatic cases, mainly as this is the group at the centre of the controversy of surgery $v s$ conservative management. In all series, elective 
resection was planned for all included patients, however $11.5 \%$ of patients from the systematic review had respiratory symptoms pre-operatively. Respiratory symptoms varied from wheeze to recurrent chest infections. This has been proposed potentially to influence not only the choice of approach, but the complexity of surgery (and outcomes).[29]

\section{Conclusion}

On the basis of available reported data, thoracoscopic resection of asymptomatic antenatally-diagnosed congenital lung malformations is associated with a (slightly) lower total complication rate, a shorter hospital stay and a longer operative time. Thoracoscopic resection is, therefore, not associated with more risks than open surgery. These data should be of use in counselling parents pre-operatively if resection of asymptomatic lung lesions is felt to be necessary.

\section{$\underline{\text { References }}$}

1. Stanton M: The argument for a non-operative approach to asymptomatic lung lesions. Semin Pediatr Surg. 2015; 24:183-186

2. Singh R, Davenport M: The argument for operative approach to asymptomatic lung lesions. Semin Pediatr Surg. 2015; 24:187-195

3. Stanton M, Njere I, Ade-Ajayi, et al: Systematic review and meta-analysis of the postnatal management of congenital cystic lung lesions. J Pediatr Surg. 2009; 44:1027-1033

4. Stocker L, Wellesley D, Stanton M, et al: The increasing incidence of foetal echogenic congenital lung malformations: an observational study. Prenat Diagnosis. $2015 ; 35: 148-153$ 
5. Lishuang M, Zhen C, Guoliang Q, et al: Laparoscopic portoenterostomy versus open portoenterostomy for the treatment of biliary atresia: a systematic review and meta-analysis of comparative studies. Pediatr Surg Int. 2015; 31:261-269.

6. Seong YW, Kang CH, Kim JT, et al: Video-assisted thoracoscopic lobectomy in children: safety, efficacy, and risk factors for conversion to thoracotomy. Ann Thorac Surg. 2013; 95:1236-42

7. Bagrodia N, Cassel S, Liao J, et al: Segmental resection for the treatment of congenital pulmonary malformations. J Pediatr Surg. 2014; 49:905-909

8. Hall NJ, Chiu PP \& Langer JC: Morbidity after elective resection of prenatally diagnosed asymptomatic congenital pulmonary airway malformations. Pediatr Pulmonol. 2016; 51:525-530

9. Nasr A \& Bass J: Thoracoscopic vs open resection of congenital lung lesions: a meta-analysis. J Pediatr Surg. 2012; 47:857-861

10. Bonnard A, Malbezin S, Ferkdadji L, et al: Pulmonary sequestration in children: is the thoracoscopic approach a good option? Surg Endosc.

2004; 18:1364-1367

11. Tölg C, Abelin K, Laudenbach V, et al: Open vs thorascopic surgical management of bronchogenic cysts. Surg Endosc. 2005; 19:77-80

12. Moher D, Liberati A, Tetzlaff J, et al: Preferred Reporting Items for Systematic Reviews and Meta-Analyses: The PRISMA Statement. Ann Intern Medicine. 2009; $151: 264-269$

13. Rangel SJ, Kelsey J, Colby CE, et al: Development of a quality assessment scale for retrospective clinical studies in pediatric surgery. J Pediatr Surg. 2003; 38:390-396 
14. Sangnawakij P, Böhning D, Adams SD, et al: Statistical methodology for estimating the mean difference in a meta-analysis without study-specific variance information. Statistics in Medicine. 2016 Submitted

15. Aziz D, Langer J, Tuuha S: Perinatally Diagnosed Asymptomatic Congenital Cystic Adenomatoid Malformation: To Resect or Not? J Pediatr Surg 2004; 39:329334

16. de Lagausie P, Bonnard A, Berrebi D, et al: Video-assisted thoracoscopic surgery for pulmonary sequestration in children. Ann Thorac Surg. 2005; 80:1266-1269 17. Jesch NK, Leonhardt J, Sumpelmann R, et al: Thoracoscopic resection of intraand extralobar pulmonary sequestration in the first 3 months of life. J Pediatr Surg. $2005 ; 40: 1404-1406$

18. Truitt AK, Carr SR, Cassese J, et al: Perinatal management of congenital cystic lung lesions in the age of minimally invasive surgery. J Pediatr Surg. 2006; 41:893896

19. Cano I, Antón-Pacheco JL, García A, Rothenberg S. Video-assisted thoracoscopic lobectomy in infants. Eur J Cardiothorac Surg. 2006; 29:997-1000

20. Diamond IR, Herrera P, Langer JC, Kim PC. Thoracoscopic versus open resection of congenital lung lesions: a case-matched study. Journal of Pediatric Surgery. 2007; 42:1057-1061

21. Sundararajan L, Parikh DH. Evolving experience with video-assisted thoracic surgery in congenital cystic lung lesions in a British pediatric center. J Pediatr Surg. 2007; 42:1243-1250

22. Albanese CT, Rothenberg SS. Experience with 144 consecutive pediatric thoracoscopic lobectomies. J Laparoendosc Adv Surg Tech A. 2007; 17:339-341 
23. Calvert JK, Lakhoo K. Antenatally suspected congenital cystic adenomatoid malformation of the lung:postnatal investigation and timing of surgery. J Pediatr Surg. $2007 ; 42: 411-414$

24. Chow P, Lee S, Tang M: Management and outcome of antenatally diagnosed congenital cystic adenomatoid malformation of the lung. Hong Kong Med J 2007;

\section{$13: 31$}

25. Vu LT, Farmer DL, Nobuhara KK, et al: Thoracoscopic versus open resection for congenital cystic adenomatoid malformations of the lung. Journal of Pediatric Surgery. 2008; 43:35-39

26. Rothenberg SS. First decade's experience with thoracoscopic lobectomy in infants and children. J Pediatr Surg. 2008; 43:40-44, discussion 45

27. Sueyoshi R, Okazaki T, Urushihara N: Managing prenatally diagnosed asymptomatic congenital cystic adenomatoid malformation. Pediatr Surg Int 2008;

24:1111-1115

28. Tsai A, Liechty, Hedrick H: Outcomes after postnatal resection of prenatally diagnosed asymptomatic cystic lung lesions. J Pediatr Surg 2008; 43:513-517 29. Rahman N, Lakhoo K. Comparison between open and thoracoscopic resection of congenital lung lesions. Journal Pediatric Surgery. 2009;44:333-336.

30. Zeidan S, Hery G, Lacroix F, et al: Intralobar sequestration associated with cystic adenomatoid malformation: diagnostic and thoracoscopic pitfalls. Surg Endosc. 2009; $23: 1750-1753$

31. Nagata K, Masumoto K, Tesiba R, et al: Outcome and treatment in an antenatally diagnosed congenital cystic adenomatoid malformation of the lung. Pediatr Surg Int. $2009 ; 25: 753-757$ 
32. Tarrado X, Castañón M, Olivares M, et al: [Thoracoscopic lobectomy: initial experience]. Cir Pediatr. 2010; 23:111-114.

33. Kaneko K, Ono Y, Tainaka T, et al: Thoracoscopic lobectomy for congenital cystic lung diseases in neonates and small infants. Pediatr Surg Int. 2010; 26:361-365 34. Ferreira HP, Fischer GB, Felicetti JC, et al: [Surgical treatment of congenital lung malformations in pediatric patients] J Bras Pneumol. 2010; 36:175-180

35. Rothenberg SS, Kuenzler KA, Middlesworth W, et al: Thoracoscopic lobectomy in infants less than $10 \mathrm{~kg}$ with prenatally diagnosed cystic lung disease. $\mathrm{J}$ Laparoendosc Adv Surg Tech A. 2011; 21:181-184

36. Boubnova J, Peycelon M, Garbi O, et al: Thoracoscopy in the management of congenital lung diseases in infancy. Surg Endosc. 2011; 25:593-596

37. Johnson SM, Grace N, Edwards MJ, et al: Thoracoscopic segmentectomy for treatment of congenital lung malformations. J Pediatr Surg. 2011; 46:2265-2269 38. Raychaudhuri P, Pasupati A, James A, et al: Prospective study of antenatally diagnosed congenital cystic adenomatoid malformations. Pediatr Surg Int. 2011; $27: 1159-1164$

39. Reismann M, Gossner J, Glueer S, et al: Thoracoscopic resection of congenital pulmonary malformations in infants: is the feasibility related to the size of the lesion? World J Pediatr. 2012; 8:272-274

40. Muller CO, Berrebi D, Kheniche A, Bonnard A. Is radical lobectomy required in congenital cystic adenomatoid malformation? J Pediatr Surg. 2012; 47:642-645 41. Cho MJ, Kim DY, Kim SC, et al: Embolization versus surgical resection of pulmonary sequestration: clinical experiences with a thoracoscopic approach. J Pediatr Surg. 2012; 47:2228-2233 
42. Fievet L, D'Journo XB, Guys JM, et al: Bronchogenic cyst: best time for surgery? Ann Thorac Surg. 2012; 94:1695-1699

43. Tanaka Y, Uchida H, Kawashima H, et al: Complete thoracoscopic versus videoassisted thoracoscopic resection of congenital lung lesions. J Laparoendosc Adv Surg Tech A. 2013; 23:719-722

44. Lau CT, Leung L, Chan IH, et al: Thoracoscopic resection of congenital cystic lung lesions is associated with better post-operative outcomes. Pediatr Surg Int. 2013; 29:341-345

45. Fascetti-Leon F, Gobbi D, Pavia SV, et al: Sparing-lung surgery for the treatment of congenital lung malformations. J Pediatr Surg. 2013; 48:1476-1480

46. Kunisaki SM, Powelson IA, Haydar B, et al: Thoracoscopic vs open lobectomy in infants and young children with congenital lung malformations. J Am Coll Surg. $2014 ; 218: 261-270$

47. Kulaylat AN, Engbrecht BW, Hollenbeak CS, et al: Comparing 30-day outcomes between thoracoscopic and open approaches for resection of pediatric congenital lung malformations: Evidence from NSQIP. J Pediatr Surg 2015; 50:1716-1721 48 Laje P, Pearson EG, Simpao AF, et al: The first 100 infant thoracoscopic lobectomies: Observations through the learning curve and comparison to open lobectomy. J Pediatr Surg 2015; 50:1811-1816

\section{Legends}

Table 1. Inclusion/Exclusion Criteria, Search Terms and Dataset for Systematic Review

Table 2. Results of Systematic Review and Quality Scoring

Figure 1. Forest plot for Total Complications 
Figure 2. Forest plot for Length of Stay in hospital 


\begin{tabular}{|c|c|}
\hline Inclusion Criteria & Exclusion Criteria \\
\hline $\begin{array}{l}\text { Published in Peer Reviewed Journal } \\
\text { Congenital lung lesion } \\
\text { Asymptomatic child }>28 \text { days old } \\
\text { All languages }\end{array}$ & $\begin{array}{l}\text { Age }<28 \text { days old } \\
\text { Age }>18 \text { years } \\
\text { Respiratory symptoms / pneumonia } \\
\text { Case Reports } \\
\text { Abstracts with unpublished papers }\end{array}$ \\
\hline \multicolumn{2}{|c|}{ Search Terms } \\
\hline $\begin{array}{l}\text { Congenital cystic adenomatous } \\
\text { malformation or CCAM } \\
\text { Thoracocotomy } \\
\text { Thoracoscopy } \\
\text { BronchoPulmonary sequestration or BPS } \\
\text { Minimally invasive Surgery or MIS } \\
\text { Pulmonary sequestration } \\
\text { Minimal Access Surgery } \\
\text { Lobectomy }\end{array}$ & $\begin{array}{l}\text { Congenital pulmonary airways } \\
\text { malformation or CPAM } \\
\text { Segmentectomy } \\
\text { Bronchogenic cyst } \\
\text { Video-assisted thorasopic surgery or } \\
\text { VATS } \\
\text { Congenital lung lesion } \\
\text { Prenatal lung lesion } \\
\text { Congenital lobar emphysema (or CLE) } \\
\text { Echogenic Lung Lesion }\end{array}$ \\
\hline \multicolumn{2}{|r|}{ Dataset } \\
\hline $\begin{array}{l}\text { Age, Sex, Weight } \\
\text { Length of follow-up } \\
\text { Number of Thoracoscopic Cases } \\
\text { Conversions to open } \\
\text { Number of open cases } \\
\text { Types of lesions excised } \\
\text { Length of operation, Length of stay }\end{array}$ & $\begin{array}{l}\text { Complications; } \\
\text { Total, death, malignancy on histology. } \\
\text { Early: bleeding, wound infection, chest } \\
\text { infection, tracheal injury, prolong air } \\
\text { leak, pneumothorax, unplanned return to } \\
\text { theatre, other } \\
\text { Late: recurrence/inadequate resection, } \\
\text { chest wall deformity, scoliosis, other }\end{array}$ \\
\hline
\end{tabular}

Table 1. Inclusion/Exclusion Criteria, Search Terms and Dataset for Systematic

Review 


\begin{tabular}{|c|c|c|c|c|c|c|c|c|c|}
\hline Ref & Author & Year & Country & $\begin{array}{c}\text { Total } \\
\text { Number }\end{array}$ & $\begin{array}{l}\text { Thoraco- } \\
\text { scopic }\end{array}$ & Open & $\begin{array}{l}\text { Conversion } \\
\text { to open }\end{array}$ & $\begin{array}{c}\text { Age at } \\
\text { surgery } \\
\text { (months) }\end{array}$ & Rangel Score \\
\hline 15 & Aziz & 2004 & Canada & 15 & 0 & 15 & N/A & 9 & 14.5 (poor) \\
\hline 11 & Tölg & 2005 & France & 8 & 4 & 4 & $1(25 \%)$ & 66 & 12.5 (poor) \\
\hline 16 & de Lagausie & 2005 & France & 8 & 8 & 0 & $2(25 \%)$ & 10 & 11 (poor) \\
\hline 17 & Jesch & 2005 & Germany & 5 & 5 & 0 & $0(0 \%)$ & 1 & 13.5 (poor) \\
\hline 18 & Truitt & 2006 & USA & 12 & 12 & 0 & $0(0 \%)$ & 10 & 5.5 (poor) \\
\hline 19 & Cano & 2006 & USA & 6 & 6 & 0 & $0(0 \%)$ & 10 & 8.5 (poor) \\
\hline 20 & Diamond & 2007 & Canada & 36 & 12 & 24 & $2(17 \%)$ & 7 & 21 (fair) \\
\hline 21 & Sundararajan & 2007 & UK & 29 & 20 & 9 & $7(35 \%)$ & 14 & 16.5 (fair) \\
\hline 22 & Albanese & 2007 & USA & 144 & 144 & 0 & $3(2 \%)$ & Not recorded & 18 (fair) \\
\hline 23 & Calvert & 2007 & UK & 16 & 0 & 16 & N/A & 8 & 7 (poor) \\
\hline 24 & Chow & 2007 & $\begin{array}{l}\text { Hong } \\
\text { Kong }\end{array}$ & 6 & 0 & 6 & N/A & 4 & 8 (poor) \\
\hline 25 & $\mathrm{Vu}$ & 2008 & USA & 36 & 12 & 24 & $6(50 \%)$ & 5 & 20.5 (fair) \\
\hline 26 & Rothenberg & 2008 & USA & 97 & 97 & 0 & $4(4 \%)$ & 46 & 11 (poor) \\
\hline 27 & Sueyoshi & 2008 & Japan & 8 & 0 & 8 & N/A & 1 & 11 (poor) \\
\hline 28 & Tsai & 2008 & USA & 105 & 0 & 105 & N/A & 3 & 12.5 (poor) \\
\hline 29 & Rahman & 2009 & UK & 28 & 14 & 14 & $1(7 \%)$ & 9 & 18 (fair) \\
\hline 30 & Zeidan & 2009 & France & 6 & 6 & 0 & $1(17 \%)$ & 5 & 10.5 (poor) \\
\hline 31 & Nagata & 2009 & Japan & 5 & 0 & 5 & N/A & 5 & 8.5 (poor) \\
\hline 32 & Tarrado & 2010 & Spain & 6 & 6 & 0 & $0(0 \%)$ & 9 & 5 (poor) \\
\hline 33 & Kaneko & 2010 & Japan & 7 & 7 & 0 & $0(0 \%)$ & 1 & 14 (poor) \\
\hline 34 & Ferreira & 2010 & Brazil & 35 & 0 & 35 & N/A & 17 & 13 (poor) \\
\hline 35 & Rothenberg & 2011 & USA & 75 & 75 & 0 & $1(1 \%)$ & 4 & 12 (poor) \\
\hline 36 & Boubnova & 2011 & France & 30 & 30 & 0 & $6(20 \%)$ & 4 & 21.5 (fair) \\
\hline 37 & Johnson & 2011 & USA & 15 & 15 & 0 & $0(0 \%)$ & Not recorded & 11 (poor) \\
\hline 38 & Raychaudhuri & 2011 & Australia & 14 & 0 & 14 & N/A & 8 & 12.5 (poor) \\
\hline 39 & Reismann & 2012 & Germany & 22 & 14 & 8 & $3(21 \%)$ & 4 & 17 (fair) \\
\hline 40 & Muller & 2012 & France & 12 & 12 & 0 & $0(0 \%)$ & 12 & 17.5 (fair) \\
\hline 41 & Cho & 2012 & Korea & 34 & 7 & 27 & $0(0 \%)$ & 61 & 20 (fair) \\
\hline 42 & Fievet & 2012 & France & 11 & 9 & 2 & $0(0 \%)$ & Not recorded & 11.5 (poor) \\
\hline 6 & Seong & 2013 & Korea & 0 & 50 & 0 & $9(18 \%)$ & 38 & 16.5 (fair) \\
\hline 43 & Tanaka & 2013 & Japan & 12 & 12 & 0 & $0(0 \%)$ & 66 & 15.5 (poor) \\
\hline 44 & Lau & 2013 & $\begin{array}{l}\text { Hong } \\
\text { Kong }\end{array}$ & 67 & 39 & 28 & $13(33 \%)$ & 11 & 22 (fair) \\
\hline 45 & Fascetti-Leon & 2013 & Italy & 54 & 26 & 28 & $18(69 \%)$ & Not recorded & 14.5 (poor) \\
\hline 46 & Kunisaki & 2014 & USA & 62 & 49 & 13 & $0(0 \%)$ & 12 & 22 (fair) \\
\hline 47 & Kulaylat & 2015 & USA & 258 & 112 & 146 & $3(3 \%)$ & 3 & 19 (fair) \\
\hline \multirow[t]{2}{*}{48} & Laje & 2015 & USA & 288 & 100 & 188 & $12(12 \%)$ & 2 & 21 (fair) \\
\hline & Total & & & 1626 & $904(56 \%)$ & 722 & $92(10 \%)$ & 15 & 13.8 (Poor) \\
\hline
\end{tabular}

Table 2. Results of Systematic Review and Quality Scoring 


\section{Total Complications}

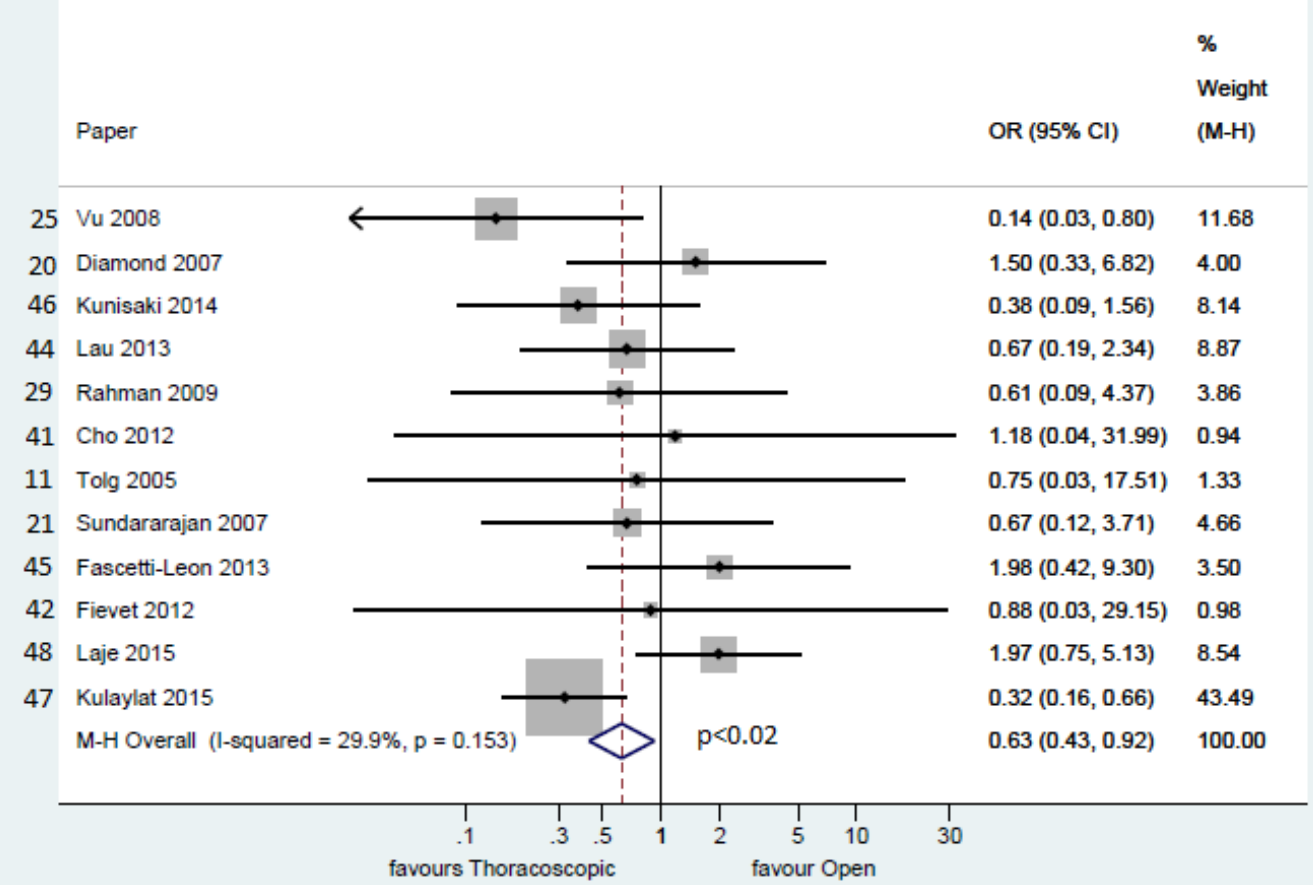

Figure 1. Forest plot for Total Complications 


\section{Length of Stay (days)}

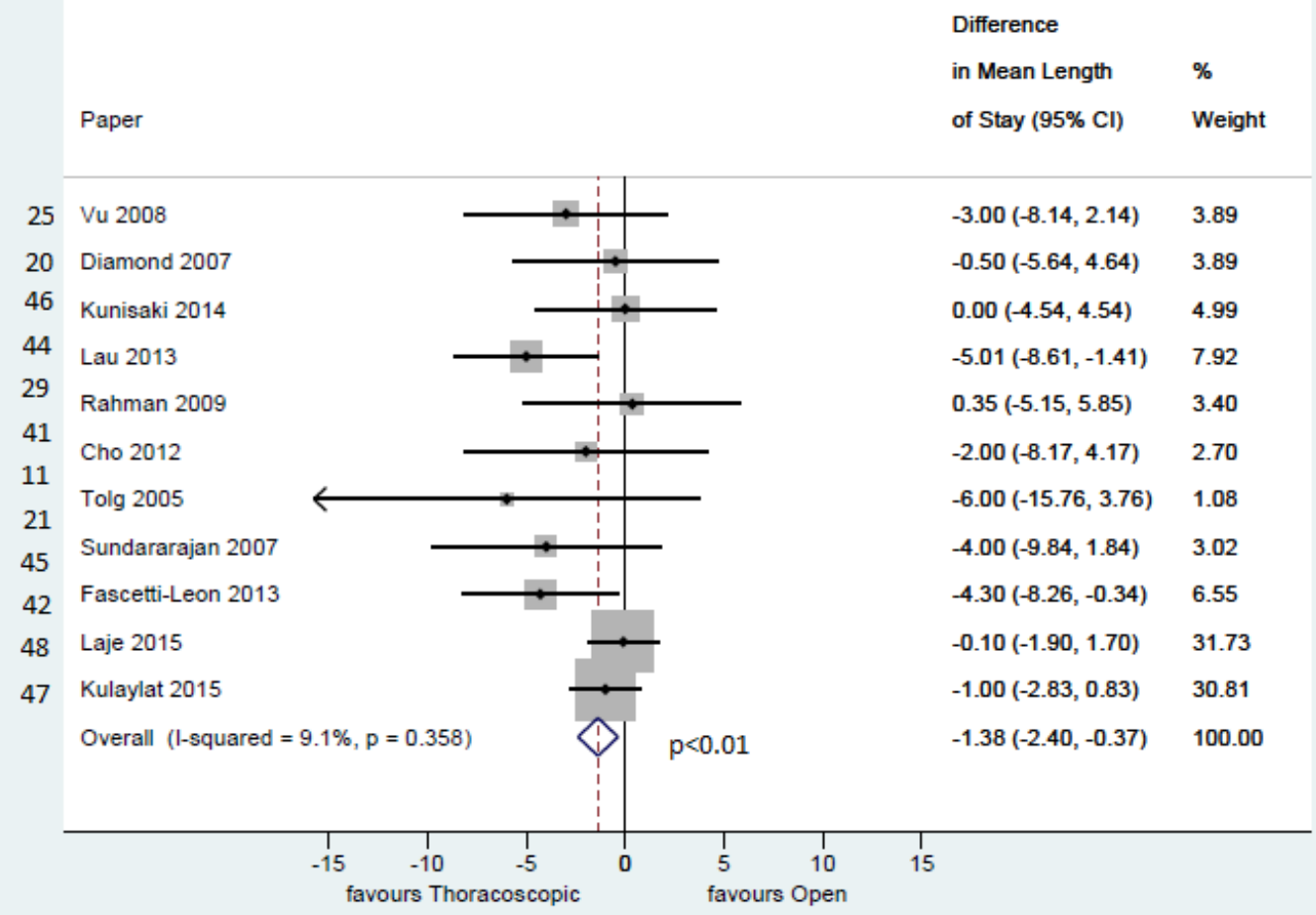

Figure 2. Forest plot for Length of Stay in hospital 